Tuckerella ormata (Tucker), UM ACARO NOVO PARA O BRASIL E OUTROS TETRANYCHOIDEA (ACARI) DO ESTADO DO PARA*

Carlos H.W. Flechtmann**

RESUMO

Assinala-se, pela primeira vez no Brasil e também pela primeira vez em cacaueiros, a presença do ácaro Tuckerelza omata (Tucker, 1926). E dada a sua relação com a planta hospedeira.

E também feita referência, para o Es tado do Pará, da presença dos ácaros Tenuipalpus heveae Baker, 1945 em seringueiras; Oligonychus mangiferus (Rahman \& Punjab, 1940)em castanhola e Tetranychus desertorum Banks, 1900 em juta.

INTRODUÇÃO

Escassas são as referências a ácaros de plantas do Estado do Parā, Brasil. A primeira citação parece ser a de BAKER (1945) quando descreveu o ácaro plano da seringueira,

\footnotetext{
* Entregue para publicação em 5.12.1979.

Com auxílio do Conselho Nacional do Desenvolvimento Cien tífico e Tecnológico, CNPq.

** Departamento de Zoologia, E.S.A."Luiz de Queiroz", USP.
} 
Tenuipalpus heveae; outras referências são as de MENDES (1967 e 1970, apud BRASIL, 1970) que citou o ácaro branco ou tropica1, Polyphagustarsonemus (sic) Latus causando danos e malformações às folhas e brotação nova da seringueira em viveiros; neste trabalho (de BRASIL, 1970) tambëm são citados Tenuipalpus sp., como ácaro vermelho que se reproduz na página inferior das folhas da seringueira e não sen do praga séria e, Paratetranychus sp., outro ácaro vermelhō e que se multiplica na página superior da folha e sendo pra ga séria durante a estação seca. Como ültima referênciā encontramos a de COSTA (1977) que relata Tetranychus mexiconzie (McGregor) infestando e prejudicando o desenvolvimento de cacaueiros enviveirados no Município de Marabá e recomendando o emprego de Malatol e Fenitrothion para o seu controle.

MATERIAL, METODOS, RESULTADOS E DISCUSSÃO

Em Outubro de 1979 tivemos oportunidade de coletar alguns ácaros de plantas em Belém, Pará; também do Centro de Pesquisa Agropecuäria do Trópico Umido (Cpatu) da Embrapa recebemos material para identificação. Com os ácaros, preservados em álcool etílico a 70\%, foram confeccionadas preparações microscópicas e cujo exame revelou a presença das seguintes espécies:

1. Famỉlia Tuckerellidae

Tuckerelza omata (Tucker, 1926) - esta espécie, cujas fêmeas se apresentam de coloração vermelho-carmim e com as expandidas setas dorsais brancas, foi encontrada em ramos de cacaueiro, Theobroma cacao L. (Sterculiaceae), na região em que a maioria dos tecidos externos já se tornou suberosa, porém, onde ainda há tecidos vivos, verdes e também abrigados em ferimentos destes ramos.

Trata-se de uma espécie de ampla distribuição geogrāfica, como se pode observar na Tabela 1 e que é, pela primeira vez, assinalada no País e em cacaueiros. 
2. Família Tenuipalpidae

Tenuipalpus heveae Baker, 1945 - este ácaro, referido no Estado do Pará como ácaro vermelho da seringueira, foi coletado da página inferior de folhas medianas e mais veThas da seringueira, Hevea sp. (Euphorbiaceae). Embora populações relativamente elevadas estivessem presentes, as folhas apresentavam-se apenas levemente enrugadas e um pouco bronzeadas.

\section{Famỉila Tetranychidae}

- Oligonychus mangiferus (Rahman \& Punjab, 1940) - este ácaro de teia foi encontrado na face superior de folhas de Terminalia catappa L. (Combretaceae), em Belém, onde a planta é conhecida por castanhola. Nesta planta, bastante empregada na arborização de ruas e quintais de casas, o áca ro desenvolve-se principalmente nas áreas do limbo foliar entre as nervuras de folhas medianas para velhas, causando intenso bronzeamento; as suas teias retêm apreciável quantidade de sujidades conferindo mau aspecto à planta.

- Tetronychus desertorum Banks, 1900 - este ácaro ver melho foi coletado pelo Dr. Antonio de Brito Silva, da Embrapa-Cpatu, de folhas de juta, Corchorus capsularis L. (Ti liaceae), no município de Alenquer, Pará, causando acentuada clorose às folhas.

SUMMARY

Tuckerella omata (Tucker), A MITE NEW FOR BRAZIL AND OTHER TETRANYCHOIDEA (ACARI) FROM THE STATE OF PARA

Tuckerella omata (Tucker) is, for the first time, recorded from Brazil (Belem, State of Parā) and also for the first time on cocoa. The female is carmine in color with white dorsal fan-like setae. It was found on woody stems of cocoa plants, where most of the outer tissues have 
turned corky, but, where areas of live tissue are still present; it was also found inside cracks of the stems.

Other Tetranychoid mites from Parä include:

- Tenuipalpus heveae Baker, found on the lower face of median to old rubber tree leaves (Hevea sp.); rather large populations were observed, causing a light leaf distortion and bronzing; it is not considered as a pest.

- Oligonychus mangiferus (Rahman \& Punjab)

causes intense leaf bronzing on Terminalia catappa L, an ornamental tree. Rather large populations of this mite were observed on the upper leaf surface; much dirt is caught in their webbings.

- Tetranychus desertorum Banks was observed damaging jute, Corchorus capsularis L., causing intense chlorosis to the leaves. Collected at Alenquer, Pará.

\section{LITERATURA CITADA}

BAKER, E.W., 1945. Mites of genus Tenuipalpus (Acarina: Trichadenidae). Proc. Entomol. Soc. Washington 47:33-38.

BAKER, E.W.; PRITCHARD, A.E., 1953. The family categories of tetranychoid mites, with a review of the new families Linotetranidae and Tuckerellidae. Ann. Entomol. Soc. Amer. 46: 243-258.

BRASIL, Superintendência da Borracha, 1970. Pragas da Seringueira. In: Heveicultura no Brasil: relatório do CEPLASE, s.1, p. 82-84.

COSTA, A.S., 1977. Principais pragas do cacaueiro no Estado do Pará. Cacau Atualidades, Ilhéus, Bahia 14(4): 1324 .

GARRETT, L.E.; HARAMOTO, F.H., 1967. A catalog of Hawaiian Acarina. Proc. Hawaiian Entomo1. Soc. 19(3):381-414. 
de LEON, D., 1955. Hosts of Tuckerella pavoniformis (Ewing) and Tuckerella ornata (Tucker) in Florida (Acarina: Tuckerellidae).Florida Entomo1. 38(2):89-90.

TUCKER, R.W.E., 1926. Some South African mites. Tetranychidae and Eriophyidae. Un. South Afr., Mainly Agric., Div. Entomol., Memoir V, 15 p. Dept. 
Tabela 1 - Distribuição geogräfica, hospedeiros e referências a Iuckereija omata (Tucker, 1926)

\begin{tabular}{|c|c|c|c|}
\hline \multicolumn{2}{|c|}{ Planta hospedeira } & \multirow{2}{*}{ Localidade } & \multirow{2}{*}{ Referência } \\
\hline Familia & Espēcie & & \\
\hline \multirow[t]{2}{*}{ Anacardiaceae } & Wongifera inciica & Hawai & $\begin{array}{l}\text { Garrett \& } \\
\text { Haramoto, } 1967\end{array}$ \\
\hline & $\begin{array}{l}\text { Scininus } \\
\text { tereointififoiius }\end{array}$ & Florida, EE.UU. & de Leon, 1955 \\
\hline Apocynaceae & $\begin{array}{l}\text { Carissa } \\
\text { grandiflora }\end{array}$ & Florida, EE.UU. & de Leon, 1955 \\
\hline Aquifoliaceae & Ilex cassini & Florida, EE.UU. & de Leon, 1955 \\
\hline Burseraceae & $\begin{array}{l}\text { Bursera } \\
\text { simamina }\end{array}$ & Florida, EE.UU. & de Leon, 1955 \\
\hline Caricaceae & Camica papaya & Hawaii & $\begin{array}{l}\text { Garrett \& } \\
\text { Haramoto, } 1967\end{array}$ \\
\hline Euphorbiaceae & Hevea sp. & Florida, EE.UU. & $\begin{array}{l}\text { Baker \& } \\
\text { Pritchard, } 1953\end{array}$ \\
\hline Guttiferae & Marmea americana & Guatemala & $\begin{array}{l}\text { Baker \& } \\
\text { Pritchard, } 1953\end{array}$ \\
\hline Lauraceae & Persea americana & Florida, EE.UU. & de Leon, 1955 \\
\hline \multirow[t]{3}{*}{$\begin{array}{l}\text { Leguminosae } \\
\text { (F abaceae) }\end{array}$} & Bauninia sp. & Florida, EE.UU. & $\begin{array}{l}\text { Baker \& } \\
\text { Pritchard, } 1955\end{array}$ \\
\hline & $\begin{array}{l}\text { Emithrina } \\
\text { sonciviaensis }\end{array}$ & Hawaii & $\begin{array}{l}\text { Garrett \& } \\
\text { Haramoto, } 1967\end{array}$ \\
\hline & Iamarincius indica & Florida, EE.UU. & de Leon, 1955 \\
\hline Wyrtaceae & Isiaium guaiava & Florida, EE.UU. & de Leon, 1955 \\
\hline Orchidaceae & Fhaiaenopsis sp. & Filipinas & $\begin{array}{l}\text { Baker \& } \\
\text { Pritchard, } 1953\end{array}$ \\
\hline \multirow[t]{4}{*}{ Rutaceae } & laranjas & África do Sul & Tucker, 1926 \\
\hline & $\because i z m w$ mi=is & Elorida, EE.uU. & de Leon, 1955 \\
\hline & $\because i=y^{2} u=$ manima & Elorida, EE.UC. & de Leon, 1955 \\
\hline & pome lo & Hawaii & $\begin{array}{l}\text { Garrett \& } \\
\text { Haramoto, } 1967\end{array}$ \\
\hline Sapotaceae & $\therefore \sin a s$ ancosa & Elorida, EE.LU. & de Leon, 1955 \\
\hline Sterculiaceae & Inaconoma zacac & Parā, Brasil & esta public. \\
\hline
\end{tabular}

